\title{
Características motivacionais no trabalho bancário: um estudo a partir da aplicação do sistema LEMO
}

Motivational characteristics in banking: a study from LEMO application

\author{
Ricardo Alberti', Felipe Cavalheiro Zaluski", \\ Lilian Cristina dos Santos Milani"', Fernando de Jesus Moreira Junior IV
}

\begin{abstract}
RESUMO
Este estudo teve como objetivo analisar os estilos de motivação predominantes em uma organização bancária, neste estudo denominada figurativamente de Banco Beta. Para isso, buscou-se descrever o perfil social dos entrevistados e analisar os níveis de satisfação e insatisfação dos funcionários e elucidar os estilos de motivação predominantes na organização. Na coleta de dados primários, aplicou-se o Levantamento dos Estilos Motivacionais (LEMO), questionário com perguntas de múltipla escolha, possuindo 36 questões fechadas. A partir das análises baseadas na estatística descritiva das informações pode-se concluir que os estilos de orientação motivacional que mais predominaram nos funcionários do Banco Beta foram os estilos ligados à ação e à manutenção e, com menor intensidade de preponderância, os estilos de motivação orientados à participação e à conciliação.
\end{abstract}

Palavras-chave: Motivação; Organização bancária; Levantamento de Estilos Motivacionais.

\begin{abstract}
This study aimed to analyze the predominant motivation styles in a banking organization, in this study figuratively called Beta Bank. To this end, we sought to describe the social profile of the interviewees and to analyze employee satisfaction and dissatisfaction levels and to elucidate the predominant styles of motivation in the organization. Primary data collection was based on Motivational Styles Survey, a questionnaire with multiple choice questions, with 36 closed questions. From the analysis based on the descriptive statistics of the information it can be concluded that the styles of motivational orientation that most predominated in the employees of Beta Bank were the styles related to action and maintenance and, with less preponderance, the styles of motivation oriented. participation and conciliation.
\end{abstract}

Keywords: Motivation; Banking organization; Survey of Motivational Styles.

\footnotetext{
'Universidade Federal de Santa Maria, Santa Maria, Brasil. E-mail: r-alberti@live.com.

"Universidade Federal de Santa Maria, Santa Maria, Brasil. E-mail: felipezaluski@hotmail.com.

III Universidade de Passo Fundo, Passo Fundo, Brasil. E-mail: liliweber@hotmail.com.

Iv Universidade Federal de Santa Maria, Santa Maria, Brasil. E-mail: fmjunior777@yahoo.com.br.
} 


\section{INTRODUÇÃO}

O modo de gerir pessoas nas organizações vem sofrendo grandes transformações. Atualmente, a motivação organizacional tornou-se um importante tema de estudo devido a sua forte relação com a gestão de pessoas e consequentemente no desempenho da busca dos objetivos organizacionais.

Neste contexto, o presente paradigma da gestão descreve que os principais recursos competitivos das organizações não são os recursos financeiros, logísticos ou tecnológicos, mas sim os indivíduos que a compõem, pois, pressupõem-se que quanto maior for a motivação, satisfação e empenho, maior será o índice de produtividade e alcance dos objetivos organizacionais (FERNANDES; CAETANO, 2000). Assim, a área de gestão de pessoas tem considerável importância nas organizações e, muito além dos controles internos de seus funcionários, tem como principal missão ordenar suas equipes em prol de resultados lucrativos para as empresas, neste contexto a motivação se torna uma importante ferramenta.

O conhecimento foi construído sobre motivação ainda não se define com precisão a sua verdadeira concepção (SILVA Jr., 2001). Entretanto, para Sampaio (2004) existe certa tendência comum em indicar que a motivação aborda o que mobiliza um funcionário a realizar algo, com forte relação aos motivos e desejos.

Ao longo dos estudos na área da motivação, muitos conhecimentos foram construídos através de pesquisas entre diversos pesquisadores, porém, ainda não se define com precisão o que é a verdadeira concepção de motivação (SILVA Jr., 2001). Entretanto, Sampaio (2004) discorre que há certa tendência comum em indicar que a motivação aborda o que mobiliza um funcionário a realizar algo, com forte relação aos motivos e desejos.

A área de estudos organizacionais da motivação humana, na gestão de pessoas, encontra-se os estilos de orientação motivacional, os quais vem de encontro com a necessidade organizacional de entender e analisar o que motiva seus funcionários e o que pode torná-los cada vez mais empenhados. Desta forma, para entender a motivação no ambiente de trabalho Bergamini (1997), após ter trabalhado e analisado o questionário LIFO, apresenta um modelo de levantamento de estilos motivacionais 
adaptado à realidade brasileira, onde identifica quatro tipos de estilos de orientação guiados pela motivação, que são classificados em quatro tipologias: Participação; Ação; Manutenção e; Conciliação.

Com base no exposto, o setor bancário surge como um cenário fundamental para analisar os estilos de orientação motivacional, pois as mudanças ocorridas no mercado, como fusões e privatizações que acarretam o fechamento de agências, diminuição do quadro de pessoal, terceirização e aumento de exigência da produtividade, torna a motivação uma variável de extrema importância (RESENDE; MENDES, 2004).

Diante de tantas mudanças, na categoria bancária, tornou-se possível controlar mais objetivamente a mão-de-obra, as chefias intermediárias foram excluídas, através da informática, as normas de controle mais objetivas foram adicionadas a uma política mais agressiva de recursos humanos no que diz respeito em motivar o funcionário para o objetivo da empresa (CENCl, 2001). Ainda, com relação à série de mudanças ocorridas no setor bancário, Cunico (2007) relata que o ritmo de trabalho mais intenso, o aumento das exigências de produtividade e qualidade, fez com que os funcionários bancários mais antigos demonstrassem sinal de desmotivação fixado na proximidade de sua aposentadoria.

Portanto, este estudo objetivou-se analisar os estilos de motivação predominantes em uma organização bancária, neste estudo denominada figurativamente de Banco Beta, localizada na região norte do Estado do Rio Grande do Sul, a qual conta com dezesseis funcionários e que atua predominantemente com o agronegócio. Para isso, buscou-se descrever o perfil social dos entrevistados e a partir da aplicação do Levantamento dos Estilos Motivacionais (LEMO) de Bergamini (1997) analisar os níveis de satisfação e insatisfação dos funcionários e elucidar os estilos de motivação predominantes na organização. 


\section{REFERENCIAL TEÓRICO}

\subsection{Motivação e o trabalho bancário}

Na administração, a motivação é a força, influenciada diretamente pelo clima das organizações que busca estimular os funcionários a trabalhar em razão dos objetivos comuns à organização, pois com uma equipe motivada, em um clima organizacional agradável, os objetivos organizacionais serão alcançados com maior facilidade (MAXIMIANO, 2004). Contudo, não se pode conceituar simplesmente a motivação como um simples ânimo que deve ser influenciada esporadicamente, pois não são apenas as influências externas, mas também as internas que motivam os indivíduos.

Neste contexto, o estudo da motivação busca explicar um dos mais complexos mistérios da existência humana, que são suas próprias ações (SILVA; RODRIGUES, 2007). Diante disso, no entendimento de Vergara (2006), o processo motivacional remete a ideia de que a motivação é algo inacabado, mas sim um processo de reconfiguração permanente. Sendo assim, a motivação é algo individual a cada pessoa, por isso ninguém consegue motivar outra pessoa, o que pode ser feito é estimular, incentivar, para que a mesma se sinta motivada.

Silva e Rodrigues (2007) descrevem que é indispensável obter conhecimento sobre a motivação humana para que realmente o gestor possa contar com a colaboração de todos os indivíduos. Nesse mesmo sentido, Robbins, Judge e Sobral (2010) buscando extrair uma definição clara de motivação a descreve como sendo um processo que desperta o desejo ou a predisposição em realizar um esforço contínuo para alcançar algum objetivo organizacional, influenciado pela capacidade da organização em satisfazer as necessidades individuais

Assim, para que os colaboradores possam realizar suas atividades, de modo a obter satisfação e motivação, é necessário que as organizações ofereçam um ambiente de trabalho confortável e seguro. Além destes fatores, evidencia-se também a importância de que sejam realizadas, no ambiente de trabalho, atividades de socialização e interação, uma vez que estes elementos se mostram de fundamental importância para a satisfação dos colaboradores com a organização e, consequentemente, maior produtividade (BORTOLOZO; SANTANA, 2011). 
Portanto, verificar a percepção dos funcionários em relação a motivação é uma abordagem relevante, pois os efeitos da falta de motivação no trabalho podem gerar inúmeros problemas tanto para as organizações quanto para os funcionários. Para as organizações, podem haver perdas de padrões de qualidade dos serviços pela falta de comprometimento e desempenho, já em relação aos funcionários, as consequências negativas podem estar ligadas a saúde física e mental, em virtude do estresse e ao absenteísmo (TAVARES, 2010; ZACCA, 2011). Estes casos vêm aumentando no setor bancário, tendo como principais causas a infraestrutura inadequada, aumento de carga de trabalho e, principalmente, a pressão por resultados positivos.

Diante disso, segundo Silva (2007), no setor bancário um dos maiores obstáculos para a gestão de pessoas é a questão motivacional, pois o funcionário bancário chega constantemente a níveis de estresse preocupantes, seja por ser necessário atingir metas estipuladas, complexidade dos produtos e serviços, burocracia institucionalizada e a busca incessante pela lucratividade que as instituições bancárias esperam em cada período. Além disso, as instituições bancárias no Brasil passaram por inúmeras transformações com a chegada da informações e modernizações tecnológicas, culminando em diversas demissões de funcionários e promovendo uma alteração na estrutura e no ambiente organizacional (SILVA, 2007).

O estudo de Nascimento (2007) retoma que as instituições bancárias devem sempre estar atentas a motivação de seus funcionários, promovendo treinamentos constantes, palestras e ações que aumentem o sentimento de pertencimento e auto realização. Desta forma, as mudanças e a competitividade das organizações afetam consideravelmente o ambiente das instituições bancárias, influenciando diretamente na percepção da motivação de seus funcionários (MALABARBA, 2015). Sob o mesmo ponto de vista, Ahammad et al. (2015) complementam que a motivação no setor bancário deve incluir práticas de avaliação de desempenho que indiquem ações para alinhar os objetivos individuais com os objetivos da organização, ainda, valorizar as contribuições dos funcionários. Os autores ainda colocam que para aumentar a motivação dos funcionários de instituições bancárias deve-se implementar sistemas de compensação que incluam critérios de remuneração e incentivos. 
Ao debruçam-se acerca do conceito de motivação, Bergamini (1997) incluí a orientação motivacional que representa uma preferência ou predisposição interna para agir. Os autores acrescentam que partindo da contribuição de Maslow, difundese que as pessoas são motivadas por necessidades, basicamente aquelas que não são totalmente satisfeitas em um determinado momento, onde ainda é possível reconhecer tendências de comportamento relativamente estáveis que caracterizam o que é conhecido como "orientação motivacional". Orientações motivacionais representam uma tentativa de identificar as manifestações das motivações básicas no ambiente de trabalho, ao invés de apenas interpretar estas motivações usando traços de personalidade auto percebidos como base (BERGAMINI, 1997).

\subsection{Estilos de orientação motivacional}

O Levantamento de Estilos Motivacionais (LEMO) elaborado por Bergamini (1997) foi concebido como uma adaptação do questionário LIFO (Life Orientation), com o qual a autora havia trabalhado por vários anos. O LIFO, criado por Atkins e Katcher (1971) e vai além do diagnóstico comportamental e propõe seis estratégias de desenvolvimento. O LEMO mantém a mesma estrutura do LIFO, porém é destinado à realidade brasileira, principalmente no que se refere à redação em Português (BERGAMINI, 1997).

Deste modo, com base nas características comportamentais dos estilos recomendados por Atkins e Katcher (1971), Bergamini (1997) relata a criação do sistema LEMO visando o levantamento de um perfil motivacional brasileiro. Validado a partir de amostras brasileiras, em que mais de 13.000 executivos foram ouvidos, o sistema LEMO foi submetido ao teste estatístico (Qui quadrado), comprovando assim a dependência entre os dois sistemas (BERGAMINI, 1997).

Ao propor o sistema LEMO, Bergamini (1997) descreve quatro estilos de orientação motivacional: Participação; Ação; Manutenção e; Conciliação. No Quadro 1 apresenta-se uma breve descrição genérica de cada estilo de orientação motivacional. 
Quadro 1 - Características pessoais de cada estilo de orientação motivacional

\begin{tabular}{|l|l|}
\hline Estilos de Orientação Motivacional & Principais características pessoais \\
\hline Participação & $\begin{array}{l}\text { Prestativos; Formadores de Talentos; Idealistas; Responsáveis; } \\
\text { Cooperadores. }\end{array}$ \\
\hline Ação & $\begin{array}{l}\text { Rápidos; Inquietos; Gostam de Competição; Convicções Firmes; } \\
\text { Lideres. }\end{array}$ \\
\hline Manutenção & Analíticos; Sensatos; Metódicos; Ponderadores; Meticulosos. \\
\hline Conciliação & $\begin{array}{l}\text { Diplomáticos; Negociadores; Entusiastas; Socialmente } \\
\text { Habilidosos; Harmonizadores. }\end{array}$ \\
\hline
\end{tabular}

Fonte: Adaptado de Bergamini (1997).

Por conseguinte, são apresentadas as condutas e características de cada estilo de orientação motivacional segundo Bergamini (1997):

1. Participação: É o indivíduo que fomenta seu desenvolvimento e aperfeiçoamento, além de valorizar o talento dos demais indivíduos da organização. Através da convivência com alguém que tem o estilo de orientação motivacional participativo é possível perceber que esse indivíduo tem eleva as exigências, assume a responsabilidades, demonstra ser leal, sensível e cooperador;

2. Ação: É guiado para aperfeiçoar a utilização de recursos e solução dos problemas de maneira eficaz. A sua descrição inclui características como facilitador, inovador e competitivo, dessa forma buscam sempre exaltar competência pessoal.

3. Manutenção: Baseia-se na análise dos fatos concretos, sendo assim é criterioso em suas análises para tomar a direção mais correta possível. Apontamentos acerca da sua personalidade indicam organização, preocupação com a continuidade das tarefas e seguridade do sucesso.

4. Conciliação: Este estilo estimula as relações humanas harmoniosas, difunde valores, valore e razoes como forma de integração da equipe. Esses indivíduos geralmente são flexíveis, diplomatas e atuam em seu trabalho de maneira positiva mostrando sensibilidade e respeito aos demais.

Essas características determinam as diferentes orientações de motivação e permitem o reconhecimento das diferenças individuais entre os funcionários. Estudos empíricos mostram que aspectos de motivação favorecem as organizações se bem alocados em funções que necessitem de habilidades específicas. A caracterização de quatro estilos de orientação básica descrevem os quatro organizadores dos diferentes estilos motivacionais (BERGAMINI, 1997). 


\section{METODOLOGIA}

A pesquisa tem um enfoque quantitativo e define-se como estudo de caso, que segundo Yin (2001) é uma pesquisa empírica que averígua um fenômeno contemporâneo dentro do contexto da vida real, principalmente quando os limites entre o fenômeno e o contexto não são visivelmente evidentes e, como descritiva, pois a pesquisa descritiva exige do investigador uma série de informações sobre o que deseja pesquisar e busca descrever os fatos e fenômenos de determinada realidade (TEIXEIRA et al., 2009).

O caso para estudo foi escolhido pela acessibilidade, conforme cita Vergara (2009), nas amostras por acessibilidade os autores selecionam os elementos a que tem facilidade para acesso, deste modo, o estudo foi realizado em uma organização bancária, denominada de Banco Beta, localizada no Estado do Rio Grande do Sul. Constituem-se a população deste estudo os dezesseis funcionários do banco em estudo, os quais foram pesquisados em sua totalidade, não havendo necessidade de utilização de amostragem, pois todos os integrantes do universo de pesquisa foram questionados, obtendo-se desta maneira um censo.

A coleta de dados ocorreu em dois momentos, com dados primários e secundários. A coleta de dados primários utilizou-se de um questionário com perguntas de múltipla escolha, possuindo 36 questões fechadas. Utiliza-se 4 questões para identificar o perfil social dos respondentes. E, a partir do questionário de Levantamento dos Estilos Motivacionais (LEMO) elaborado por Bergamini (1997), utiliza-se 32 questões agrupadas em 4 grupos de situações para identificar os níveis de satisfação dos funcionários e 4 grupos de situações para identificar os níveis de insatisfação dos funcionários. Cada grupo de situações geradora de satisfação ou insatisfação possui 4 afirmativas com cenários onde os funcionários deveriam assinalar o que provoca em si mais satisfação ou mais insatisfação. Já a coleta de dados secundários utilizou-se da pesquisa bibliográfica, pois conforme cita Fonseca (2002), é elaborada a partir do levantamento de referências teóricas já analisadas, e publicadas por meios escritos e eletrônicos, como livros, artigos científicos, páginas de web sites. 
Para a análise dos dados coletados foi utilizada a estatística descritiva com distribuição de frequências (f), percentuais (\%), sendo utilizado o software Excel para tabulação dos dados.

\section{RESULTADOS E DISCUSSÃO}

O caso estudado, Banco Beta, é uma organização bancária de economia mista que oferece produtos, serviços e informações para o atendimento das necessidades dos clientes e a cada segmento de mercado. A organização, está localizada no norte do Estado do Rio Grande do Sul e possui dezesseis funcionários, sendo que um desempenha o papel de gerente do banco, cinco são gerentes de módulo, dois são assistentes de negócios, três são operadores de caixa e cinco são escriturários. O atendimento aos clientes está segmentado em níveis de relacionamento (pessoa física e pessoa jurídica) além do autoatendimento e do atendimento nos caixas.

Deste modo, a seguir, apresenta-se o perfil dos entrevistados para melhor analise das informações e, após, os fatores higiênicos e motivacionais elucidados na pesquisa.

\subsection{Perfil dos entrevistados}

O levantamento do perfil social dos entrevistados buscou elucidar as variáveis de: sexo; faixa etária; tempo de serviço (na organização em estudo) e escolaridade, conforme apresentado no Tabela 1:

Em uma análise geral dos dados é possível notar que do perfil é possível caracterizar os funcionários do Banco Beta como sendo predominantemente do gênero masculino, com concentração da faixa etária a partir dos 31 anos, Rodrigues (1999 apud ABREU; SORJ, 2002) explica que a concentração nessa faixa etária resulta de um processo de envelhecimento da categoria bancária ao longo da década de noventa. Ainda, o Banco Beta se caracteriza em ter funcionários com pelo menos 6 a mais de 15 anos no Banco, assim como Abreu e Sorj (2002) argumentam, as mudanças ocorridas fazem com que as instituições bancárias se empenhem para fortalecer os vínculos entre os bancários e a organização, assegurando maior estabilidade aos seus 
funcionários, pois cerca de metade deles (48\%) permanece no mesmo banco há 10 anos. Considera-se um perfil com a maioria dos funcionários possui além do nível superior de ensino com $1 / 4$ deles estudando atualmente, coincidindo com as informações de Abreu e Sorj (2002) o qual aponta que a evolução do grau de instrução da categoria bancária acelerou extremamente.

Tabela 1 - Perfil dos entrevistados

\begin{tabular}{llll}
\hline Variáveis & Variáveis & Frequência $(f)$ & Percentual (\%) \\
\hline \multirow{3}{*}{ Sexo } & Feminino & 2 & $12,5 \%$ \\
& Masculino & 14 & $87,5 \%$ \\
& Total & 16 & $100 \%$ \\
\multirow{5}{*}{ Faixa etária } & $18-25$ anos & 2 & $12,5 \%$ \\
& $26-30$ anos & 3 & $18,75 \%$ \\
& $31-35$ anos & 3 & $18,75 \%$ \\
& $36-40$ anos & 4 & $25 \%$ \\
& Mais de 40 anos & 4 & $25 \%$ \\
& Total & 16 & $100 \%$ \\
Tempo de serviço & De 6 a 10 anos & 0 & $0 \%$ \\
& Menos de 1 ano & 4 & $25 \%$ \\
& De 1 a 3 anos 15 anos & 1 & $6,25 \%$ \\
& Mais de 15 anos & 6 & $25 \%$ \\
& Total & 16 & $6,25 \%$ \\
& Ensino médio & 5 & $37,5 \%$ \\
& Superior incompleto & 2 & $31,25 \%$ \\
Escolaridade & Superior completo & 3 & $12,5 \%$ \\
& Pós-Graduação & 1 & $18,75 \%$ \\
& incompleta & 5 & $6,25 \%$ \\
& Pós-Graduação completa & 5 & $31,25 \%$ \\
& Total & 16 & $100 \%$ \\
\hline
\end{tabular}

Fonte: Dados da pesquisa (2017).

\subsection{Estilos de orientação motivacional}

A partir da coleta de dados quanto as questões do sistema LEMO (BERGAMINI, 1997), apresenta-se a seguir as análises das situações geradoras de satisfação e situações geradoras de insatisfação, por fim, destaca-se o resultado total das respostas com base nas situações que causam satisfação ou insatisfação para, então, se chegar ao estilo de orientação motivacional predominante nos funcionários do Banco Beta.

\subsubsection{Situações que causam satisfação}

A seguir são apresentadas quatro tabelas as quais contém quatro situações que causam satisfação (BERGAMINI, 1997). Cada situação orienta para um estilo 
motivacional: 1 - Participação; 2 - Ação; 3 - Manutenção e 4 - Conciliação. As questões foram analisadas com o objetivo de identificar qual o estilo motivacional predominante nos funcionários do Banco Beta em cada situação geradora de satisfação e, a partir disso, os resultados são analisados nas tabelas a seguir:

Tabela 2 - Situações geradoras de satisfação I

\begin{tabular}{lcc}
\hline Questões & Frequência(f) & Percentual (\%) \\
\hline 1 - Estar sintonizado com a orientação do meu grupo de trabalho & 1 & $6,25 \%$ \\
2 - Ser desafiado e comprovar minha eficiência & 7 & $43,75 \%$ \\
3 - Atividades que me oportunizem usar a lógica e organização & 1 & $6,25 \%$ \\
4 - Estar num ambiente em que existe harmonia entre as pessoas & 7 & $43,75 \%$ \\
\hline Soma & 16 & $100 \%$ \\
\hline \multicolumn{1}{c}{ Fonte: Dados de pesquisa (2017). } & &
\end{tabular}

Analisando a Tabela 2, onde se apresenta as situações geradoras de satisfação I, é possível verificar que as questões 2 e 4 tiveram o mesmo percentual de respostas, ou seja, 43,75\% dos funcionários possuem um estilo motivacional orientado para a ação e outros $43,75 \%$ dos funcionários um estilo motivacional orientado para a manutenção. Ainda, 6,25\% dos funcionários apresentam características do estilo motivacional orientado para a participação e $6,25 \%$ dos funcionários orientação do estilo de motivação de conciliação.

Tabela 3 - Situações geradoras de satisfação II

\begin{tabular}{lll}
\hline Questões & Frequência $(f)$ & Percentual (\%) \\
\hline 1 - Poder consultar os colegas e ser consultado por eles & 5 & $31,25 \%$ \\
2 - Ter autonomia para realizar meu trabalho e tomar decisões & 3 & $18,75 \%$ \\
3 - Ter o tempo necessário para garantir a qualidade do meu & 6 & $37,50 \%$ \\
trabalho & 2 & $12,50 \%$ \\
4- Trabalhar em um ambiente flexível & 16 & $100 \%$ \\
\hline Soma & &
\end{tabular}

Fonte: Dados de pesquisa (2017).

De acordo com Tabela 3, onde destaca-se as situações geradoras de satisfação II, pode-se dizer que $37,50 \%$ dos funcionários possuem um estilo motivacional orientado para a manutenção, logo em seguida, com 31,25\% dos funcionários identifica-se um estilo motivacional orientado para a participação. O estilo de motivação orientado para a ação ficou com $18,75 \%$ das respostas dos funcionários e o estilo de orientação motivacional voltado para a conciliação apresentou $12,50 \%$ das respostas dos mesmos. 
Tabela 4 - Situações geradoras de satisfação III

\begin{tabular}{lcc}
\hline Questões & Frequência $(f)$ & Percentual (\%) \\
\hline 1 - Poder usar seus talentos pessoais para & 1 & $6,25 \%$ \\
o desenvolvimento da organização & 4 & $25,00 \%$ \\
2 - Poder desenvolver atividades variadas & 5 & $31,25 \%$ \\
3 - Dispor de fontes confiáveis de consulta e informação & 6 & $37,50 \%$ \\
4 - Sentir que sou importante dentro do meu grupo & 16 & $100 \%$ \\
\hline Soma
\end{tabular}

Fonte: Dados de pesquisa (2017).

De acordo com Tabela 4, onde apresenta-se as situações geradoras de satisfação III, verifica-se que 37,50\% dos funcionários têm o um estilo de orientação motivacional orientado para a conciliação, 31,25\% têm um estilo motivacional orientado para a manutenção, $25 \%$ orientados para a ação e $6,25 \%$ possuem um estilo de motivação orientado para a participação.

Tabela 5 - Situações geradoras de satisfação IV

\begin{tabular}{lcc}
\hline Questões & Frequência $(f)$ & Percentual (\%) \\
\hline 1 - Poder promover os talentos daqueles com quem trabalho & 4 & $25,00 \%$ \\
2 - Ser tratado de igual para igual & 3 & $18,75 \%$ \\
3 - Sentir que há coerência e justiça no trato com as pessoas & 8 & $50,00 \%$ \\
4 - Poder conhecer a contribuição social de minhas ações & 1 & $6,25 \%$ \\
\hline Soma & 16 & $100 \%$ \\
\hline
\end{tabular}

Fonte: Dados de pesquisa (2017).

Com relação Tabela 5, onde é destacado as situações geradoras de satisfação IV, pode-se dizer que a metade dos funcionários, 50\%, possui um estilo motivacional orientado para a manutenção, $25 \%$ dos funcionários tem um estilo de orientação motivacional participativo, $18,75 \%$ dos funcionários apresentam o estilo de motivação orientado para a ação e apenas 6,25\% dos funcionários possuem orientação motivacional voltada para a conciliação.

A Tabela 6, apresenta a descrição geral das respostas das situações geradoras de satisfação analisadas nas tabelas anteriores.

Tabela 6 - Análise geral das situações geradoras de satisfação

\begin{tabular}{lcccccccc}
\hline Questões & Tabela 2 & Tabela 3 & Tabela 4 & Tabela 5 & Total & Percentual & Média & Desvio Padrão \\
\hline 1 (Participação) & 1 & 5 & 1 & 4 & 11 & $17,19 \%$ & 2,75 & 1,785357 \\
2 (Ação) & 7 & 3 & 4 & 3 & 17 & $26,56 \%$ & 4,25 & 1,63936 \\
3 (Manutenção) & 1 & 6 & 5 & 8 & 20 & $31,25 \%$ & 5 & 2,54951 \\
4 (Conciliação) & 7 & 2 & 6 & 1 & 16 & $25,00 \%$ & 4 & 2,54951 \\
Soma & 16 & 16 & 16 & 16 & 64 & $100 \%$ & & \\
\hline
\end{tabular}

Fonte: Dados de pesquisa (2017). 
Analisando a Tabela 6, a partir da análise geral das situações geradoras de satisfação, pode-se dizer que o estilo motivacional orientado para manutenção predomina, até a presente análise, com 31,25\% do total de respostas dos funcionários, seguido do estilo de motivação orientado para a ação com $26,56 \%$ do total de respostas. O estilo de motivação orientado para a conciliação apresentou 25\% do total de respostas e o estilo de motivação voltado para a participação apresenta-se com 17,19\% do total de respostas dos funcionários. A maior frequência média foi a de motivação por manutenção (5) seguido por motivação por ação $(4,25)$.

Segundo as afirmativas é possível perceber que existe certo equilíbrio entre os respondentes, de maneira que a diferença entre participação que demonstrou o menor índice e manutenção que demonstrou ser o maior é próximo da média de perfeito equilíbrio (25\%). Segundo Bergamini (1997) as pessoas são motivadas por necessidades que não são satisfeitas em determinado momento, e essas necessidades variam de indivíduo para individuo. Sendo assim uma equipe equilibrada entre as motivações torna-se mais eficaz no ambiente laboral, através da integração, ajuda mútua e foco no objetivo da organização.

De maneira empírica é possível perceber que já ocorreram mudanças desde o estudo de Cunico (2007), pois apesar do aumento de exigências de produtividade e qualidade os funcionários mostraram uma motivação equilibrada com todas as dimensões de análise. Na sequência será realizada a análise quanto a insatisfação dos colaboradores.

\subsubsection{Situações que causam insatisfação}

A seguir são apresentadas quatro tabelas as quais contém quatro situações que causam insatisfação (BERGAMINI, 1997). Cada situação orienta para um estilo motivacional: 1 - Participação; 2 - Ação; 3 - Manutenção e 4 - Conciliação. As questões foram analisadas com o objetivo de identificar qual o estilo motivacional predominante nos funcionários do Banco Beta em cada situação geradora de insatisfação e, a partir disso, os resultados são analisados nas tabelas a seguir: 
Tabela 7 - Situações geradoras de insatisfação I

\begin{tabular}{lcc}
\hline Questões & Frequência $(f)$ & Percentual (\%) \\
\hline 1 - Ser tratado de forma impessoal & 2 & $12,50 \%$ \\
2 - Ter minha ação restrita & 3 & $18,75 \%$ \\
3 - Trabalhar com informações confusas e incorretas & 9 & $56,25 \%$ \\
4 - Sentir-me diminuído diante do meu grupo & 2 & $12,50 \%$ \\
\hline Soma & 16 & $100 \%$ \\
\hline
\end{tabular}

Fonte: Dados de pesquisa (2017).

De acordo com a análise da Tabela 7, onde é apresentado as situações geradoras de insatisfação I, 56,25\% dos funcionários, mais da metade, possuem um estilo motivacional orientado para a manutenção, seguindo de 18,75\% dos funcionários apresentam estilo de motivação voltado para a ação, 12,50\% dos funcionários possuem orientação motivacional orientada para a participação e, também, 12,50\% voltado para a orientação motivacional de conciliação.

Tabela 8 - Situações geradoras de insatisfação II

\begin{tabular}{lll}
\hline Questões & Frequência $(f)$ & Percentual (\%) \\
\hline 1 - Desenvolver atividades sem significado & 3 & $18,75 \%$ \\
2 - Trabalhar sem ter de objetivos claros & 9 & $56,25 \%$ \\
3 - Estar sujeito a um clima de constantes mudanças. & 3 & $18,75 \%$ \\
4 - Precisar seguir normas e horários rígidos & 1 & $6,25 \%$ \\
\hline Soma & 16 & $100 \%$ \\
\hline
\end{tabular}

Fonte: Dados de pesquisa (2017).

De acordo com a segunda Tabela 8, onde destaca-se as situações geradoras de insatisfação II, 56,25\% dos funcionários tem um estilo motivacional orientado para ação, $18,75 \%$ dos funcionários possuem orientação motivacional voltada para a participação, 18,75\% também possuem orientação motivacional para a manutenção e 6,25\% dos funcionários possuem estilo de motivação orientada para a conciliação.

Tabela 9 - Situações geradoras de insatisfação III

\begin{tabular}{lcc}
\hline Questões & Frequência $(f)$ & Percentual (\%) \\
\hline 1 - Sentir que minhas intenções não são reconhecidas & 6 & $37,50 \%$ \\
2 - Falta de responsabilidade dos demais & 9 & $56,25 \%$ \\
3 - Conviver com pessoas dadas a explosões emocionais & 1 & $6,25 \%$ \\
4 - Sentir-me socialmente colocado de lado & - & - \\
\hline Soma & 16 & $100 \%$ \\
\hline
\end{tabular}

Fonte: Dados de pesquisa (2017). 
De acordo com a Tabela 9, onde analisa-se as situações geradores de insatisfação III, a maioria das respostas, 56,25\%, indica funcionários orientados para o estilo de motivação de ação, seguido por $37,50 \%$ orientados para o estilo motivacional de participação e apenas $6,25 \%$ dos funcionários são orientados para o estilo motivacional de manutenção.

Tabela 10 - Situações geradoras de insatisfação IV

\begin{tabular}{lcc}
\hline Questões & Frequência $(f)$ & Percentual (\%) \\
\hline 1 - Conviver em meio a um clima de falsidade & 6 & $37,50 \%$ \\
2 - Não ter controle de variáveis que afetam os resultados & 2 & $12,50 \%$ \\
3 - Tratar os assuntos de forma incompleta e superficial & 7 & $43,75 \%$ \\
4 - Estar em um ambiente sério demais em que as pessoas se & 1 & $6,25 \%$ \\
atritam constantemente & 16 & $100 \%$ \\
\hline Soma
\end{tabular}

Fonte: Dados de pesquisa (2017).

Quanto à Tabela 10, que elucida das situações geradores de insatisfação IV, 43,75\% dos funcionários são orientados para a manutenção e, logo após, o maior número de respostas, $37,50 \%$, define funcionários com orientação participativa. 0 estilo de motivação orientada para a ação aparece em 12,50\% dos funcionários e apenas $6,25 \%$ dos funcionários apresentam estilo de motivação orientada para a conciliação.

A Tabela 11 apresenta a descrição geral das respostas das situações geradoras de satisfação analisadas nas tabelas anteriores:

Tabela 11 - Análise geral das situações geradoras de insatisfação

\begin{tabular}{lcccccccc}
\hline Questões & Tabela 6 & Tabela 7 & Tabela 8 & Tabela 9 & Total & Percentual & Média & Desvio Padrão \\
\hline 1 (Participação) & 2 & 3 & 6 & 6 & 17 & $26,56 \%$ & 4,25 & 1,785357 \\
2 (Ação) & 3 & 9 & 9 & 2 & 23 & $35,94 \%$ & 5,75 & 3,269174 \\
3 (Manutenção) & 9 & 3 & 1 & 7 & 20 & $31,25 \%$ & 5 & 3,162278 \\
4 (Conciliação) & 2 & 1 & - & 1 & 4 & $6,25 \%$ & 1 & 0,707107 \\
\hline Soma & 16 & 16 & 16 & 16 & 64 & $100 \%$ & & \\
\hline
\end{tabular}

Fonte: Dados de pesquisa (2017).

Analisando a Tabela 11, que destaca a análise geral das respostas com relação a situações geradoras de insatisfação, percebe-se que $35,94 \%$ do total de respostas dos funcionários possui orientação motivacional para a ação e 31,25\% do total de respostas dos funcionários para a manutenção. Destaca-se ainda $26,56 \%$ do total de respostas 
dos funcionários com estilo de motivação orientado para a participação e 6,25\% orientados para a conciliação. A maior frequência média encontrada é referente a ação $(5,75)$, que demonstrou o maior desvio padrão $(3,27)$.

Diferentemente das situações que geram motivação, as ações que geram insatisfação demonstram certo desequilíbrio, em especial a ação e manutenção. 0 aspecto motivacional da conciliação quando ocorre à insatisfação deve ser difundido para a promoção de atitudes mais flexíveis e respeitosas entre colegas de trabalho (Bergamini, 1997). Isso demonstra que a organização tem cuidado com o lado humano dos funcionários. Porém em contra partida eles esperam que as ações da organização tenham um desempenho melhor, já que foi o item que mais mostrou insatisfação $(35,94 \%)$.

Atitudes que podem ser difundidas para o combate da insatisfação com as ações da organização podem surgir de atividades de socialização e interação, onde o funcionário que presta o atendimento diretamente ao cliente tem a oportunidade de indicar melhorias tornando a empresa mais assertiva (BORTOLOZO; SANTANA, 2011). Levar em conta a percepção dos funcionários evita a falta de motivação no trabalho e a perda no padrão de qualidade (TAVARES, 2010; ZACCA, 2011).

4.2.3 Análise Geral das Situações que Causam Satisfação e Insatisfação

A Tabela 12 apresenta o resultado total das respostas com base nas situações que causam satisfação e nas que causam insatisfação.

Tabela 12 - Análise geral das situações geradoras de satisfação e insatisfação

\begin{tabular}{lcccccc}
\hline Questões & $\begin{array}{c}\text { Total geral da Tabela 5 } \\
\text { (satisfação) }\end{array}$ & $\begin{array}{c}\text { Total geral da Tabela 11 } \\
\text { (insatisfação) }\end{array}$ & $\begin{array}{c}\text { Soma } \\
\text { geral }\end{array}$ & $\begin{array}{c}\text { Percentual } \\
\text { (\%) }\end{array}$ & $\begin{array}{c}\text { Média } \\
\text { geral }\end{array}$ & $\begin{array}{c}\text { Desvio Padrão } \\
\text { geral }\end{array}$ \\
\hline 1 (Participação) & 11 & 17 & 28 & $21,88 \%$ & 3,5 & 1,936492 \\
2 (Ação) & 17 & 23 & 40 & $31,25 \%$ & 5 & 2,692582 \\
3 (Manutenção) & 20 & 20 & 40 & $31,25 \%$ & 5 & 2,872281 \\
4 (Conciliação) & 16 & 16 & 20 & $15,62 \%$ & 2,5 & 2,397916 \\
Soma & 64 & 64 & 128 & $100 \%$ & & \\
\hline
\end{tabular}

Fonte: Dados de pesquisa (2017).

A partir da análise geral das situações que causam satisfação e insatisfação percebe-se que, em média, 31,25\% dos funcionários possuem estilo de motivação orientada para a ação e, também, 31,25\%, em média, possuem estilo de motivação orientado para a manutenção, ou seja, os dois estilos supracitados são os mais 
predominantes nos funcionários do Banco Beta. Ainda, 21,88\% dos funcionários, em média, possuem estilo de motivação orientado para a participação e apenas 15,62\% dos funcionários, em média, possuem estilo de motivação orientado para a conciliação. A média geral reforça a afirmação do percentual, e o desvio padrão demonstrou que a motivação por ação foi de 2,69 , um pouco menor do que a por manutenção $(2,87)$.

Os resultados mostraram igualdade com relação à motivação pra manutenção e para a conciliação. Dessa forma percebe-se que com relação à motivação dos funcionários a manutenção foi o mais pontuado tanto para a satisfação quanto para a insatisfação, Bergamini (1997) coloca que para esse funcionário a organização interna com os indivíduos, procedimentos e sistemas tem que estar perfeita para que a organização atinja seus objetivos, por isso quem demonstra esse tipo de motivação nunca está confortável com o estado atual e sempre procura algo com o que melhorar.

O maior reflexo da insatisfação foi com relação a ação, que vem de encontro aos estudos de Bortolozo e Santana (2011), e esse resultado é esperado pois no setor bancário nem sempre o funcionário que está nas agências tem voz ativa a ações que a organização vai tomar, e isso é um fator de insatisfação. A participação e a conciliação foram os fatores que menos geraram satisfação e insatisfação, entende-se essa postura através do fomento que é dado por atingimento de metas e seguimento de protocolos, o que leva os funcionários a se motivar mais através da ação e da manutenção (SILVA, 2007).

\section{CONCLUSÃO}

A partir das análises das informações coletadas com o sistema LEMO de Bergamini (1997) pode-se concluir que os estilos de orientação motivacional que mais predominaram nos funcionários do Banco Beta foram os estilos ligados à ação e à manutenção e, com menor intensidade de preponderância, os estilos de motivação orientados à participação e à conciliação.

Neste contexto, com maior predominância, o estilo de orientação motivacional de ação é de extrema importância para o Banco Beta, pois busca envolver os funcionários para que estejam prontos a enfrentar um determinado desafio em suas 
rotinas, além de possuir espírito inovador bem como convicções firmes, tendo propensão a convencer facilmente os demais, este estilo de orientação motivacional reflete funcionários capazes de aproveitar as oportunidades existentes e apresentarem considerável pro atividade.

Ainda, apresentando maior predominância, o estilo de orientação motivacional de manutenção é mais refletido na lógica, na análise dos fatos concretos, bem como no cuidado constante em determinar a melhor linha de ação possível de conduta, antes de passarem à ação concreta, sendo que este tipo de orientação motivacional é de importante no Banco Beta, visto a necessidade de organização de atividades, horários, documentações e definição de prioridades pelos funcionários. A utilização da lógica de raciocínio e sistematização pelos funcionários deste estilo de orientação motivacional facilita as análises de dados concretos dos demonstrativos financeiros visando a evitar erros e perdas, sendo um estilo de orientação motivacional oportuna quando se considera os modelos burocráticos instalados neste tipo de organização.

O estilo de orientação motivacional de participação apresentou baixa predominância, portanto, denotando um comportamento mais individualista presente nas instituições bancárias. A participação como estilo de orientação motivacional proporciona nos funcionários uma crescente busca por aperfeiçoar-se e desenvolverse profissionalmente, possibilitando que o Banco Beta apresente maior qualidade de atendimento e prestação de seus serviços, nesta conjuntura, este estio de orientação motivacional possibilitaria a maior cooperação dos funcionários na resolução de problemas comuns do banco.

Com a menor influência, elucida-se o estilo de orientação motivacional de conciliação que em um contexto do ambiente do Banco Beta seria importante para harmonizar as relações entre funcionários, clientes, fornecedores, etc., ou seja, este estilo de orientação motivacional auxiliaria em criar um ambiente harmonioso e demonstrando respeito e grande sensibilidade às expectativas dos outros. Outro importante fator que este estilo motivacional promove é o interesse em conhecimento do maior número de pessoas, relações interpessoais e amizades o que promoveria aumento da prospecção de clientes para o Banco Beta. 
Diante disso, percebe-se que os funcionários possuem os quatro estilos de orientação do comportamento motivacional. O que as diferencia entre si é a ênfase com que utilizam essas quatro diretrizes, sendo que esse composto de estilos de orientação motivacional depende da valorização dada por cada um dos funcionários aos diferentes fatores de satisfação ou insatisfação motivacional que estejam disponíveis. Pode-se assim considerar que existe um primeiro, um segundo e até mesmo um terceiro estilo pessoal, de acordo com a frequência que aparece nos comportamentos habituais da pessoa. O quarto estilo, também conhecido como força negligenciada, representa o comportamento que a pessoa desejaria evitar, devido à insegurança de colocá-lo em prática. Um aspecto a ser observado é que exista o equilíbrio entre os quatro estilos de modo que a organização possa gozar de todos os benefícios que cada um dispõe.

O estudo mostrou limitações por investigar somente uma unidade do Banco Beta, indica-se para estudos futuros a aplicação em mais unidades possibilitando a conferencia e correlação dos resultados encontrados neste setor. Outra possibilidade que surgiu através dessa pesquisa é a possibilidade de exploração de cada um dos fatores individualmente principalmente os fatores motivacionais acerca da ação e manutenção que foram os mais citados pelos funcionários. 


\section{REFERÊNCIAS}

ABREU ARP, SORJ B. O emprego feminino no setor bancário. Inovações tecnológicas e práticas de estabilização. In: LAVINAS L, LEÓN F. (Org). Políticas Sociales. Santiago de Chile: CEPAL, 2002.

AHAMMAD MF, LEE SM, MALUL M, SHOHAM A. Behavioral Ambidexterity: The Impact of Incentive Schemes on Productivity, Motivation, and Performance of Employees in Commercial Banks. Human Resource Management, v. 54, n. 1, p. 45-62, 2017.

ATKINS S, KATCHER A. Life orientations survey. Beverly Hills, CA: LIFO Associates, 1971.

BERGAMINI CW. Motivação nas organizações. 4. ed. São Paulo, Atlas, 1997.

BORTOLOZO A, SANTANA DD. Qualidade de vida no trabalho: os fatores que melhoram a qualidade de vida no trabalho. In: Simpósio Nacional de Iniciação Científica. I, 2008. Londrina. Anais eletrônicos... Londrina: UNIFIL, 2011.

CENCI, CMB. Sofrimento psíquico no trabalho bancário. 1.ed. Passo Fundo, 2001.

CUNICO SL. A motivação dos funcionários do Banco do Brasil: um olhar sobre a agência de Guarapuava/PR. 36. 2007. Monografia (Especialização em negócios Financeiros) - Programa de Pós-Graduação em Administração. Universidade Federal do Rio Grande do Sul (UFRGS), Curitiba, 2007.

FERNANDES A, CAETANO A. Gestão de Recursos Humanos: contextos, processos e técnicas. Lisboa: Editora $\mathrm{RH}, 2000$.

FONSECA JJS. da. Metodologia da pesquisa científica. Ceará: Universidade Estadual do Ceará, 2002.

MALABARBA MB. Motivação no setor bancário: um estudo dos funcionários do banco de Lage Landen Brasil. 65. 2015. Monografia (Bacharelado em Administração) - Departamento de Ciências Administrativas. Universidade Federal do Rio Grande do Sul (UFRGS), Porto Alegre, 2015.

MAXIMIANO ACA. Introdução a administração. 6 ed. São Paulo: Atlas, 2003.

NASCIMENTO, RSGF. Rorschach Compreensive Systen data for a sample of 409 adult nonpatients from Brazil. Journal of Personality Assessment, v. 89, n. 1, p. 35-41, 2007.

RESENDE S, MENDES, AM. A sobrevivência como estratégia para suportar o sofrimento no trabalho bancário. Revista Psicologia: Organizações e Trabalho, Florianópolis, v. 4, n. 1, p. 151-175, 2004. 
ROBBINS SP, JUDGE TA, SOBRAL F. Comportamento Organizacional - teoria e prática no contexto brasileiro. 14a ed. São Paulo: Pearson Prentice Hall, 2010.

SAMPAIO JR. Voluntários: um estudo sobre a motivação de pessoas e cultura em uma organização do terceiro setor. 65. 2004. Tese (Doutorado em Administração) Faculdade de Economia, Administração e Contabilidade. Universidade de São Paulo (USP), São Paulo, 2004.

SILVA Jr NA. Satisfação no trabalho: um estudo entre os funcionários dos hotéis de João Pessoa. Psico-USF (Impr.), Itatiba, v. 6, n. 1, p. 47-57, 2001.

SILVA PS. Motivação - a realidade do funcionalismo do Banco do Brasil em Santa Cruz do Sul (RS). 78. 2007. Dissertação (Pós-Graduação em Administração) Universidade Federal do Rio Grande do Sul (UFRGS). Porto Alegre, 2007.

SILVA WR, RODRIGUES, CMC. Motivação nas organizações. São Paulo, Atlas, 2007.

TAVARES MSRA. Motivação e desempenho dos funcionários da Administração Pública Cabo-Verdiana Actual. 2002. 2010. Dissertação (Mestrado em Gestão) Universidade Aberta Lisboa (UAB), Lisboa, 2010.

TEIXEIRA EB, ZAMBERLAN L, RASIA PC. Pesquisa em Administração. Ijuí: Ed. Unijuí, 2009.

VERGARA SC. Gestão de pessoas. 5.ed. São Paulo, Atlas, 2006.

2009.

Projetos e relatórios de pesquisa em administração. 10 ed. São Paulo: Atlas,

YIN RK. Estudo de caso - planejamento e métodos. 2. ed. Porto Alegre: Bookman. 2001.

ZACCA CN. Motivação no Emprego Público: um estudo de caso numa empresa pública do setor bancário. 50. 2011. Monografia (Pós-graduação em Administração Pública Contemporânea) - Programa de Pós-Graduação em Administração da Escola de Administração. Universidade Federal do Rio Grande do Sul (UFRGS), Porto Alegre, 2011. 